\title{
TRAINING LOAD AND RECOVERY STATUS DURING A SHORT-TERM OVERSEAS TRAINING CAMP IN TAIWAN FUTSAL PLAYERS
}

original paper

(1) University School of Physical Education in Wroclaw

DOI: https://doi.org/10.5114/hm.2018.83218

\author{
YU-XIAN LU ${ }^{1}$, FILIPE MANUEL CLEMENTE ${ }^{2,3}$, JOSE PEDRO BEZERRA ${ }^{2,4}$, \\ YUNG-SHENG CHEN ${ }^{1}$ \\ ${ }^{1}$ Department of Exercise and Health Sciences, University of Taipei, Taipei, Taiwan \\ ${ }^{2}$ Polytechnic Institute of Viana do Castelo, School of Sport and Leisure, Viana do Castelo, Portugal \\ ${ }^{3}$ Instituto de Telecomunicações, Covilhã, Portugal \\ ${ }^{4}$ Research Center in Sports Sciences, Health Sciences and Human Development (CIDESD), UTAD University, Vila Real, \\ Portugal
}

\begin{abstract}
Purpose. The purpose of the study was to examine the physiological performance profiles and recovery status in a men futsal team during a short-term overseas training camp.

Methods. Among 11 Chinese Taipei men national futsal players, we determined the average heart rate (HR), the natural $\log$ of the square root of the mean sum of the squared differences between R-R intervals (LnrMSSD), and activity profiles, as well as applied a wellness questionnaire and a recovery scoring guide during a 5-day overseas training camp with 2 training matches.

Results. For activity profiles, speed zone $2\left(5.0-7.9 \mathrm{~km} \cdot \mathrm{h}^{-1}, p=0.01\right)$, zone $3\left(8.0-11.9 \mathrm{~km} \cdot \mathrm{h}^{-1}, p<0.01\right)$, zone 4 $\left(12.0-17.9 \mathrm{~km} \cdot \mathrm{h}^{-1}, p=0.01\right)$, and deceleration zone $2\left(1.0-1.99 \mathrm{~m} \cdot \mathrm{s}^{-2}, p=0.01\right)$ on the $2^{\text {nd }}$ match day were significantly larger than those on the $1^{\text {st }}$ match day. The $2^{\text {nd }}$ match day showed a smaller percentage of HR zone 1 (50-59\% of HRmax, $p=0.04)$ than the $1^{\text {st }}$ match day. The wellness questionnaire, recovery scoring guide, resting HR, and LnrMSSD presented no significant difference across the training camp $(p>0.05)$.

Conclusions. The absence of fluctuation in the recovery status and resting cardiac responses is not associated with changes in training and match loads. The players' recovery status and intensity of running patterns during an overseas futsal training camp were not influenced by the accumulation of training loads in a short-term period.
\end{abstract}

Key words: training load, heart rate, recovery status, congested schedule, futsal

\section{Introduction}

Futsal is a high-intensity indoor sport, characterized by a similar nature of physical activities and game principles as football [1]. The game is usually played with team members of 4 outfield players and 1 goalkeeper in indoor sport facility. It requires the outfield players to move around the pitch with high frequency change in the defence, offense, and transition phases [2]. Most often, futsal players need to facilitate rotation of movement or combination of play in attempt to create space during offensive and tran- sition phases. The nature of the sport makes players perform high-intensity exertion of multiple-direction running in short distance, and acceleration and deceleration of body movement; it also demands perceptual skills [3, 4].

Futsal players physically require anaerobic and aerobic components to match the demand of the game. In terms of anaerobic performance, locomotion activities changed in every 8-9 seconds, indicating the nature of intermittent exercise in futsal [5]. Futsal players perform high speed running and sprint in about $22.5 \%$ of total covering distance during a regu-

Correspondence address: Yung-Sheng Chen, Department of Exercise and Health Sciences, University of Taipei, No. 101, Sec. 2, Jhongcheng Rd., Shihlin Dist., Taipei 11153, Taiwan, e-mail: yschen@utaipei.edu.tw

Received: September 29, 2018

Accepted for publication: February 11, 2019

Citation: Lu YX, Clemente FM, Bezerra JP, Chen YS. Training load and recovery status during a short-term overseas training camp in taiwan futsal players. Hum Mov. 2018;19(5)special/issue:98-105; doi: https://doi.org/10.5114/hm.2018.83218. 
lar competition [6]. In terms of aerobic performance, the maximum oxygen uptake of professional futsal players is around $60 \mathrm{ml} \cdot \mathrm{kg}^{-1} \cdot \mathrm{min}^{-1}$ [7]. The players spend the majority of match time with over $85 \%$ of maximum heart rate $\left(\mathrm{HR}_{\max }\right)$ and the intensity range of physical exertion of heart rate (HR) responses of $170-190$ beats $\cdot \min ^{-1}[3,6]$. Therefore, the physical demand during a futsal match is relatively high, with aerobic and anaerobic metabolisms.

Monitoring training intensity and workloads has been received as a great opportunity to enhance exercise performance and to prevent injuries in athletes [8]. Adjustment of training loads (TL) in various time points is essential to optimize physiological and psychological conditions for competition [9]. For the external TL, methods for measuring speed, acceleration, time-motion analysis have been extensively used to assess the quantification of movement patterns [10]. In addition, recording internal load can provide information regarding physiological and psychological characteristics in relation to acute and chronic training adaptation. One of the methods to quantify the internal TL is to record the session rating of perceived exertion (sRPE) [11]. This simple tool provides subjective information on the accumulation of physical exertion, based upon weekly/monthly/seasonal/annual periods. For example, Miloski et al. [12] observed futsal players' TL with sRPE over a 37-week season. The results revealed higher TL during the preparation period than in the competition period. Fluctuation of TL, aiming to fit the fixture of matches, was also observed during the competition period. Another method to record the internal TL is to measure HR responses and the variability of cardiac patterns (HR variability, HRV). Sports practitioners now commonly observe changes in the vagal-related HRV index: the natural log of the square root of the mean sum of the squared differences between R-R intervals (LnrMSSD) in a series of time periods. This measurement can be used to understand the autonomic modulation as related to training adaptation [13]. For example, Nakamura et al. [14] applied LnrMSSD to compare the HRV in professional futsal players during a pre-season training. The results revealed a decrease in coefficient variation of LnrMSSD as a result of physiological adaptation at the end of 5-week pre-season training.

It is important to note that a congested schedule of training sessions or competitions can serve as a heavy burden to players' physiological and psychological status [15]. Most studies use exercise HR responses and activity profiles (e.g. motion profile) to assess the training and match intensities for short- and long- term adaptations owing to convenience and practical considerations [16-18]. However, the efficient methods to monitor external and internal loads during congested matches are controversial. Rabbani et al. [19] reported that Hooper index had higher sensitivity to associate exercise workload (sRPE) than HRV indices during 4 consecutive days of a football tournament. Whether monitor tools for assessing TL are related to recovery status during a congested schedule of a short-term overseas futsal training camp is not fully clear. In this study, we investigated external loads (activity profiles) and internal loads (HR and sRPE), and the recovery status of futsal players during a short-term overseas camp. The aims of the study were: (1) to examine the external training/match load during a short-term overseas camp; (2) to examine the internal training/match load and recovery status during a shortterm overseas camp.

\section{Material and methods}

\section{Participants}

Overall, 11 male futsal players from Chinese Taipei (Taiwan) national futsal team were recruited in the present study. Goalkeepers were excluded as their position performance and training are absolutely different than in the case of outfield players. The $1^{\text {st }}$ day of the overseas training camp was a travelling day. Body height, weight, and composition were measured, respectively, with a stadiometer (Seca 213, Seca, Germany), electrical weight scales (Xyfwt382, TECO, Taiwan), and a skinfold caliper (Lange Skinfold Caliper, Beta Technology, USA). The anthropometric characteristics (Table 1) were determined in the hotel prior to travelling. One outfield player missed the anthropometric measurements and was not included in data analysis. Four skinfold thicknesses were used to assess the percentage of body fat by a sports trainer. The percentage of body fat was obtained with the use of the following formula [20]:

\section{$5.783+0.153 *$ (the sum of triceps, subscapular, suprailiac, abdominal skinfolds) / 100}

Fat mass was determined with the equation:

$$
\text { body fact percentage }{ }^{*} \text { body weight }{ }^{*} 100^{-1}
$$

The percentage of muscle mass was established with the formula:

$$
\text { muscle mass * } 100 * \text { total body } \text { mass }^{-1}
$$


Table 1. The anthropometric characteristics of the futsal players in the present study

\begin{tabular}{lr}
\cline { 2 - 2 } & \multicolumn{1}{c}{ Baseline } \\
\hline Age (years) & $22.8 \pm 4.7$ \\
Height $(\mathrm{cm})$ & $171.9 \pm 4.9$ \\
Weight $(\mathrm{kg})$ & $68.1 \pm 5.2$ \\
Fat mass $(\mathrm{kg})$ & $7.9 \pm 1.7$ \\
Muscular mass (kg) & $31.2 \pm 2.6$ \\
Bone mass (kg) & $12.6 \pm 1.2$ \\
Percent of fat (\%) & $11.6 \pm 1.9$ \\
Percent of muscle (\%) & $45.8 \pm 2.3$ \\
Percent of bone (\%) & $18.5 \pm 1.3$ \\
\hline
\end{tabular}

Muscle mass was calculated with the use of Matiegka's formula [21]:

$$
\begin{aligned}
& \text { body weight }- \text { (fat weight }+ \text { bone weight }+ \\
& \text { residual weight) }
\end{aligned}
$$
[22]:

Bone weight was obtained from Rocha's equation

bone mass $(\mathrm{kg})=3.02 *$ [height $(\mathrm{m})^{2} *$ wrist breadth $(\mathrm{m}) *$ femur breadth $(\mathrm{m}) * 400] * 0.712$

The calculation of residual weight followed the formula [23]:

$$
\text { total body mass * } 24.1 * 100^{-1}
$$

One more formula applied was as follows:

$$
\begin{gathered}
\text { bone percentage }(\%)=\text { bone weight } * 100 * \\
\text { total body mass }{ }^{-1}
\end{gathered}
$$

\section{Experimental procedures}

The team schedule consisted of 3 training sessions and 2 training matches with the Thailand professional futsal teams in Bangkok. The $1^{\text {st }}$ day was a travelling day, it included one 2-hour training session at 4 p.m. On the $2^{\text {nd }}$ and $4^{\text {th }}$ days, there were training matches with Highways Futsal Club at 5 p.m. and Royal Thai Navy Futsal Club at 3 p.m., respectively. The $3^{\text {rd }}$ day consisted of two 2-hour training sessions: at 10 a.m. and 4 p.m. The $5^{\text {th }}$ day was a travelling day without any training or match load. A qualified sports trainer recorded all the players' recovery status and resting HR between 7:00 to 9:00 a.m. All players were informed about the time to sleep at 10 p.m. during the camp. HR zone, activity profile, and sRPE were recorded during the training sessions and training matches.
Training and match loads

To monitor the training and match workloads, we used a telemetry device with a team HR monitor system (Polar Team Pro, Polar, Finland) that recorded the HR responses and activity profiles.

The participants mounted the HR straps on the chest and checked the availability of data detection prior to the data collection. The HR zones were divided into 5 levels (HR zone 1: $50-59 \%$ of $\mathrm{HR}_{\max }$, HR zone 2: $60-69 \%$ of $\mathrm{HR}_{\max }$, HR zone 3: $70-79 \%$ of $\mathrm{HR}_{\max }$, HR zone $4: 80-89 \%$ of $\mathrm{HR}_{\max }$, HR zone 5: $90-100 \%$ of $\left.\mathrm{HR}_{\max }\right)$. Age-predicted HR (220 - age) was used to determine the $\mathrm{HR}_{\max }$. The HR responses below 50\% of $\mathrm{HR}_{\max }$ were not included in data analysis.

The activity profile was recorded with Polar Team Pro sensors, which consisted of MEMS motion sensors with the frequency of $200 \mathrm{~Hz}$. The measurements included total covering distance, number of sprints, speed zone, acceleration, and deceleration. The threshold of sprint was set with $24.0 \mathrm{~km} \cdot \mathrm{h}^{-1}$. Speed zones were determined as follows: zone $1: 1.0-4.9 \mathrm{~km} \cdot \mathrm{h}^{-1}$, zone 2: $5.0-7.9 \mathrm{~km} \cdot \mathrm{h}^{-1}$, zone $3: 8.0-11.9 \mathrm{~km} \cdot \mathrm{h}^{-1}$, zone 4 : $12.0-17.9 \mathrm{~km} \cdot \mathrm{h}^{-1}$, and zone $5: \geqslant 18.0 \mathrm{~km} \cdot \mathrm{h}^{-1}$ [7]. Acceleration and deceleration zones were defined as: zone 1: $0.50-0.99 \mathrm{~m} \cdot \mathrm{s}^{-2}$, zone 2: $1.0-1.99 \mathrm{~m} \cdot \mathrm{s}^{-2}$, zone 3: $2.0-2.99 \mathrm{~m} \cdot \mathrm{s}^{-2}$, and zone $4: 3.0-50.0 \mathrm{~m} \cdot \mathrm{s}^{-2}$.

For the subjective TL, the Borg CR10 scale was used to calculate sRPE in arbitrary units [24] as RPE score multiplied by training or match duration. In addition, Dalhousie dyspnoea and perceived exertion scales were applied to evaluate the muscular and respiratory perceptions during training sessions and matches [25]. The response of subjective TL was reported individually within 1 hour after the training session.

\section{Recovery status}

During this overseas training camp, all players were required to measure the resting HR in the morning prior to the breakfast. The Polar system was used to measure their resting HR and HRV in a sitting position. All players were instructed to sit for 5 minutes, followed by 5 minutes of data collection. The HR data were then exported to the Polar Team Pro web service. For the HRV analysis, Kubios HRV analysis software (Premium version 3.0, Kubios, Finland) was used to calculate LnrMSSD.

The recovery scoring guide and the wellness questionnaire were also applied to assess internal TL and recovery status. The recovery scoring guide consisted of a total of 20 points for nutrition, hydration, sleep, 
relaxation, stretch exercise [26]. In turn, the wellness questionnaire involved 5 components to assess fatigue, sleep quality, general muscle soreness, stress level, and mood. The total score of the 5 components was used to evaluate the general aspect of recovery conditions [27].

\section{Statistical procedures}

The descriptive data of the measured variables were presented as mean \pm standard deviation $(S D)$. One-way repeated measurement of analysis of variance (ANOVA) was used to compare the total covering distance, number of sprints, and recovery status. Two-way repeated measurement of ANOVA (days $\times$ levels) served to compare the HR, speed, acceleration, and deceleration zones. When a significant main effect or interaction was found, a post-hoc analysis with Bonferroni was conducted to identify the locations of significant differences. The effect size $(E S)$ was ascribed the following levels: small effect $(E S<0.5)$, moderate effect $(0.5 \leq E S<0.8)$, and large effect $(E S \geq 0.8)$ [28]. An alpha value of 0.05 was set for significant differences between the means. All statistical analyses were performed with the SigmaPlot software version 13 for Windows (Systat Software, USA).

\section{Ethical approval}

The research related to human use has been complied with all the relevant national regulations and institutional policies, has followed the tenets of the Declaration of Helsinki, and has been approved by the authors' institutional review board or an equivalent committee.

\section{Informed consent}

Informed consent has been obtained from all individuals included in this study, who were informed on the risk of the participation.

\section{Results}

For activity profiles, the main effects (days and levels) and interaction were significantly different in the speed, acceleration, and deceleration zones $(p<0.01)$. The results showed that speed zone $2(p<0.01, E S=1.12)$, zone $3(p<0.01, E S=1.42)$, zone $4(p<0.01, E S=1.14)$, and deceleration of zone $2(p<0.01, E S=1.35)$ on the $2^{\text {nd }}$ match day were significantly larger than those on the $1^{\text {st }}$ match day (Figures 1 and 2).

For the measurement of HR zone, significant differences were found in main effects (days and levels) and interaction $(p<0.01)$. HR zone 1 on the $2^{\text {nd }}$ match

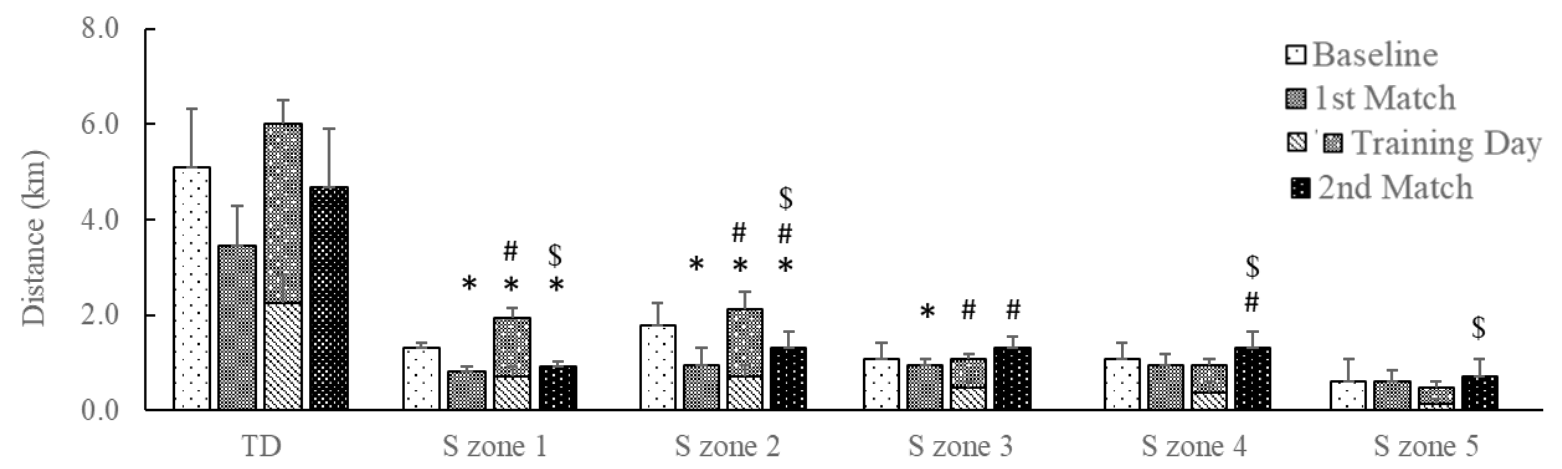

TD - total distance, S - speed; * significant difference with the baseline day; \# significant difference with the $1^{\text {st }}$ match; $\$$ significant difference with the training day

Figure 1. Activity profiles in total covering distance and speed zone during the overseas training camp

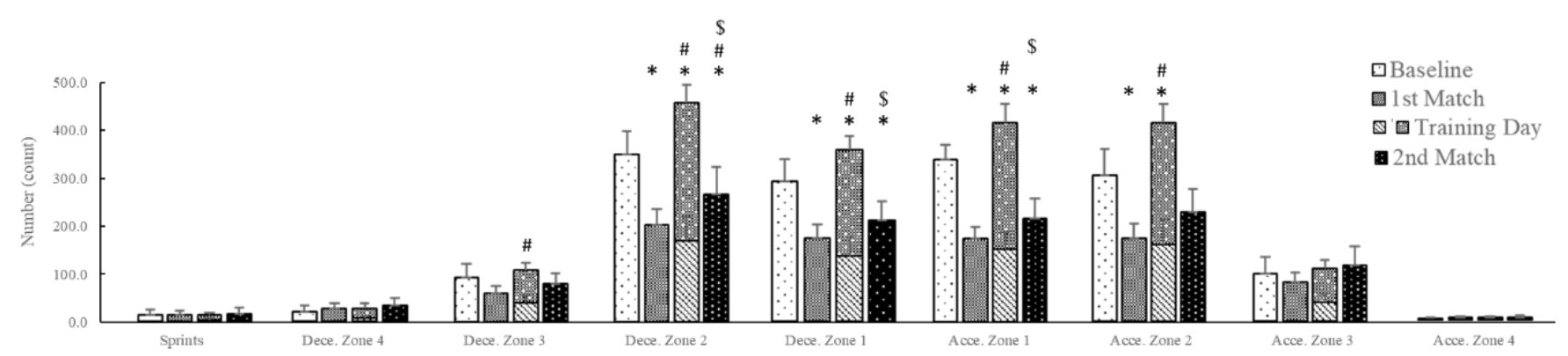

Dece - deceleration, Acce - acceleration; * significant difference with the baseline day; \# significant difference with the $1^{\text {st }}$ match; $\$$ significant difference with the training day

Figure 2. Acceleration and deceleration running patterns during the overseas training camp 
Y.X. Lu, F.M. Clemente, J.P. Bezerra, Y.-S. Chen, Training load and recovery status

Table 2. The objective training load as indicated by heart rate zone during the overseas training camp

\begin{tabular}{lcccc} 
& $\begin{array}{c}\text { Day 1 } \\
\text { (baseline) }\end{array}$ & $\begin{array}{c}\text { Day 2 } \\
\left(1^{\text {st }} \text { match) }\right.\end{array}$ & $\begin{array}{c}\text { Day 3 } \\
\text { (training day) }\end{array}$ & $\begin{array}{c}\text { Day 4 } \\
\left(2^{\text {nd }} \text { match) }\right.\end{array}$ \\
\hline HR zone 1 (\%) & $26.5 \pm 8.2$ & $30.4 \pm 15.2$ & $17.6 \pm 6.0^{* \#}$ & $14.7 \pm 11.2^{* *}$ \\
HR zone 2 (\%) & $17.4 \pm 7.6$ & $26.3 \pm 12.0^{*}$ & $18.5 \pm 3.3^{\#}$ & $27.3 \pm 8.1^{* \$}$ \\
HR zone 3 (\%) & $11.8 \pm 5.4$ & $15.1 \pm 7.5$ & $13.9 \pm 3.9$ & $20.5 \pm 10.0^{*}$ \\
HR zone 4 (\%) & $8.0 \pm 4.8$ & $8.1 \pm 2.8$ & $11.4 \pm 5.5$ & $7.6 \pm 3.3$ \\
HR zone 5 (\%) & $4.4 \pm 4.8$ & $13.9 \pm 6.4^{*}$ & $4.6 \pm 4.9^{\#}$ & $17.2 \pm 7.8^{* \$}$ \\
\hline
\end{tabular}

HR - heart rate; * significant difference with the baseline day; ${ }^{\#}$ significant difference with the $1^{\text {st }}$ match;

$\$$ significant difference with the training day

Table 3. The subjective training load during the training camp including the rating of perceived exertion and the respiratory and muscular rating of perceived exertion

\begin{tabular}{lcccc} 
& $\begin{array}{c}\text { Day 1 } \\
\text { (baseline) }\end{array}$ & $\begin{array}{c}\text { Day 2 } \\
\left(1^{\text {st }} \text { match) }\right.\end{array}$ & $\begin{array}{c}\text { Day 3 } \\
\text { (training day) }\end{array}$ & $\begin{array}{c}\text { Day 4 } \\
\left(2^{\text {nd }} \text { match }\right)\end{array}$ \\
\hline RPE & $3.6 \pm 1.0$ & $4.7 \pm 1.3$ & $3.2 \pm 0.9$ & $6.4 \pm 2.0 * \$$ \\
Respiratory RPE & $3.0 \pm 0.9$ & $3.7 \pm 0.9$ & $2.7 \pm 0.7$ & $4.5 \pm 1.3 * \$$ \\
Muscular RPE & $2.7 \pm 1.4$ & $3.3 \pm 1.2$ & $2.5 \pm 1.1$ & $4.2 \pm 1.1^{* \$}$ \\
Session-RPE (AU) & $511.2 \pm 137.2$ & $438.7 \pm 124.4$ & $563.2 \pm 161.7$ & $716.8 \pm 219.0^{* \#}$ \\
\hline
\end{tabular}

$\mathrm{RPE}$ - rating of perceived exertion, AU - arbitrary units; * significant difference with the baseline day;

\# significant difference with the $1^{\text {st }}$ match; ${ }^{\$}$ significant difference with the training day

Table 4. The scores of recovery status in general wellness questionnaire, recovery scoring guide, and cardiac responses during the overseas training camp

\begin{tabular}{|c|c|c|c|c|}
\hline & $\begin{array}{c}\text { Day } 2 \\
\left(1^{\text {st }} \text { match }\right)\end{array}$ & $\begin{array}{c}\text { Day } 3 \\
\text { (training day) }\end{array}$ & $\begin{array}{c}\text { Day } 4 \\
\left(2^{\text {nd }} \text { match }\right)\end{array}$ & $\begin{array}{c}\text { Day } 5 \\
\text { (travelling day) }\end{array}$ \\
\hline \multicolumn{5}{|l|}{ General wellness } \\
\hline Total score & $18.6 \pm 2.7$ & $17.2 \pm 2.6$ & $18.2 \pm 1.9$ & $17.5 \pm 0.7$ \\
\hline Fatigue & $3.2 \pm 1.1$ & $2.9 \pm 0.9$ & $3.2 \pm 0.8$ & $2.9 \pm 0.3$ \\
\hline Sleep & $4.3 \pm 0.5$ & $4.0 \pm 0.5$ & $4.0 \pm 0.5$ & $4.0 \pm 0.5$ \\
\hline General muscle soreness & $3.3 \pm 1.1$ & $2.9 \pm 1.0$ & $3.2 \pm 0.8$ & $3.2 \pm 0.6$ \\
\hline Stress level & $3.4 \pm 0.7$ & $3.5 \pm 0.7$ & $3.5 \pm 0.7$ & $3.2 \pm 0.6$ \\
\hline Mood & $4.4 \pm 0.5$ & $3.9 \pm 0.9$ & $4.3 \pm 0.5$ & $4.2 \pm 0.4$ \\
\hline \multicolumn{5}{|l|}{ Recovery quality } \\
\hline Recovery scoring guide & $18.8 \pm 1.0$ & $18.9 \pm 1.0$ & $18.7 \pm 0.7$ & $18.8 \pm 0.6$ \\
\hline \multicolumn{5}{|l|}{ Cardiac responses } \\
\hline Resting heart rate (bpm) & $56.5 \pm 4.6$ & $56.5 \pm 5.7$ & $59.1 \pm 4.5$ & $58.8 \pm 6.4$ \\
\hline LnrMSSD (ms) & $4.0 \pm 0.4$ & $4.1 \pm 0.4$ & $4.0 \pm 0.3$ & $3.9 \pm 0.4$ \\
\hline
\end{tabular}

LnrMSSD - natural logarithm of the root mean square differences between adjacent normal R-R intervals

day was significantly smaller than that on baseline day $(p<0.01, E S=1.20)$ and on the $1^{\text {st }}$ match day $(p<0.01$, $E S=0.90$; Table 2). In contrast, HR zone 5 on the $2^{\text {nd }}$ match day was significantly larger than that on baseline day $(p<0.01, E S=1.98)$ and training day $(p<0.01$, $E S=1.93)$.

The results showed that a main effect (days) was found in RPE, respiratory RPE, muscular RPE, and sRPE. The post-hoc analysis revealed that the $2^{\text {nd }}$ match day presented significantly larger values than the baseline day and training day in respiratory RPE and muscular RPE $(p<0.05)$. In addition, the RPE and sRPE on the $2^{\text {nd }}$ match day were significantly larger than those on baseline day $(p<0.01, E S=1.82 ; p<0.01, E S=1.13$, respectively) and on the $1^{\text {st }}$ match day $(p<0.01, E S=$ 1.04; $p<0.01, E S=1.56$, respectively; Table 3).

General wellness, recovery scoring guide, resting HR, and LnrMSSD showed no significant differences in statistical analysis ( $p>0.05$; Table 4$)$. 


\section{Discussion}

The main findings in the present study were that the recovery status, resting HR, and HRV showed no between-day significant differences during the shortterm overseas training camp. In addition, the players spent a high proportion of time spent in HR zone 1 in the $1^{\text {st }}$ match, compared with the $2^{\text {nd }}$ match, whereas speed zone 2 , zone 3 , zone 4 , and deceleration zone 2 were significantly larger on the $2^{\text {nd }}$ match day compared with the $1^{\text {st }}$ match day. The study assumed that the match intensity measured by HR and activity profiles on the $2^{\text {nd }}$ match day was not influenced by the accumulation of TL in the short-term period.

\section{External training/match loads}

The activity profiles in the present study showed that the total covering distance equalled $3430.7 \pm 764.8 \mathrm{~m}$ and $4642.4 \pm 1219.2 \mathrm{~m}$ in the $1^{\text {st }}$ match and the $2^{\text {nd }}$ match, respectively. Makaje et al. [7] reported that the activity profiles of the Thailand professional futsal league included $5087 \mathrm{~m}$ of total covering distance. Compared with the study by Makaje et al., our study showed lower total covering distance in the training matches against the Thailand professional futsal team. Barbero-Alvarez et al. [6] reported a total covering distance of $5091 \mathrm{~m}$ in the Spanish professional futsal league. The covering distance close to $5000 \mathrm{~m}$ indicated a rigorous match intensity with movement patters of various speed running. Moreover, deceleration zone 2 and speed zones 2-4 were larger in the $2^{\text {nd }}$ match than in the $1^{\text {st }}$ match, indicating a high demand of performance in medium-intensity running and change of speed against the match with the Thai Navy Futsal Club. However, we did not observe any significant change in the numbers of sprints, high-intensity speed running, acceleration, or deceleration between the matches. It is possible to assume that less activity performance in the $1^{\text {st }}$ match was due to inadequate low and medium running performance, compared with the $2^{\text {nd }}$ match. The tactical tasks and game strategies are potential factors to change the match intensity.

\section{Internal training/match loads}

The results of the present study demonstrated that the players spent a high proportion of time in HR zone 1 in the $1^{\text {st }}$ match compared with the $2^{\text {nd }}$ match. HR zone 3 and HR zone 5 were higher in the $2^{\text {nd }}$ match, although the difference did not approach statistical significance. These findings indicate high physiological stress in aerobic and anaerobic conditions in the $2^{\text {nd }}$ match. Rodrigues et al. [29] demonstrated that the mean match intensity in the $1^{\text {st }}$ division of the Brazilian futsal league was around $86.4 \pm 3.8 \% \mathrm{HR}_{\max }$. Makaje et al. [7] also observed an average of $89.8 \% \mathrm{HR}_{\max }$ during matches in the Thailand professional futsal league. The lower average HR intensity reported in our study may be due to the methodological difference of HR recording. We recorded HR throughout the training matches, including time spent on and off pitch. Another factor to cause lower average HR responses was related to the tactical tasks and game strategies. Clemente and Nikolaidis [30] found that futsal players spent $60 \%$ of training time over the HR zones above $70 \% \mathrm{HR}_{\max }$. However, our study only observed around $24-29 \%$ of time spent on above $70 \% \mathrm{HR}_{\max }$ during training sessions. This is because of the training tasks (e.g. rotation, set piece, etc.) and absence of physical domain of the training session prior to the training matches.

HRV is a useful tool to assess the recovery status in relation to autonomic modulation in sports training. It is suggested to use the time-domain HRV indices of LnrMSSD to monitor the weekly internal TL and daily change in the training status [31]. The results of the present study demonstrated no change in the morning cardiac responses by assessing resting HR and LnrMSSD in a short-term overseas training camp. Plews et al. [32] suggested that an increase in weekly LnrMSSD associated with a decrease in resting HR represented the elevation of parasympathetic activation. In contrast, a decrease in weekly LnrMSSD associated with an increase in resting HR indicates fatigue or overtraining status. The reciprocal relationship between the weekly LnrMSSD and resting HR can be used as a physiological indication to monitor recovery status. Nakamura et al. [14] compared the coefficient variation of HRV in 10 professional futsal players during a 5-week pre-season phase. The study reported that the vagal-related index LnrMSSD decreased its coefficient and variation in the 5-week training. The physiological scenario behind this phenomenon was related to physiological adaptation in cardiac vagal activation. The advantage of LnrMSSD use is that the measurement is not limited by the respiratory factors. Buchheit [33] suggested a positive correlation of long-term training adaptation and modulation of weekly LnrMSSD. An increase in weekly LnrMSSD indicates an optimal result of training adaptation. However, it may not be applicable to measure daily morning HRV in team sports without specific practitioners and proper equipment. 


\section{Recovery status}

Wellness measurement is a time-efficient and easy tool to monitor the recovery status during sports training. Rabbani et al. [19] suggested that a general wellness questionnaire is a more sensitive tool to assess internal loads than LnrMSSD and $S D$ of normal to normal R wave (SDNN) during a congested match schedule in collegiate football players. However, we found no difference of wellness scores associated with LnrMSSD across the 5-day measurement, despite accumulation of training and match loads. The players in the present study had less stressful travelling schedule on the $1^{\text {st }}$ day and the tactical practice during the training day focused on set pieces, combination play, and power play. In addition, comfortable living environment and dining service may have been potential factors to facilitate optimal psychometric responses and nutritional contents in the present study as reflected by high scores in the wellness questionnaire and recovery scoring guide. Thus, the organization of the travelling itinerary, living environment, accessibility of sports facilities, and kit management are essential factors to impact the recovery status.

\section{Functional implication}

It is now widely accepted to observe the training and match intensities by using HR zone measurement in team sports [17]. The information of HR patterns can help us to understand the internal training and match loads for a long-term training period or a competitive season [33]. Since professional futsal leagues are not as widespread as football ones, most countries recruit national A team players on the basis of semi-professional and/or amateur levels. In this case, a short-term training camp is applicable. From coaches' point of view, implantation of overseas training camps to neighbourhood countries is a practical solution to analyse the strength and weakness of team performance prior to a major tournament. Congested schedule is often organized by coaches owing to time limitation for game preparation. In this case, it is necessary to monitor the psychometric status and activity profiles in addition to HR responses in all players. Considerations for the training routine and the time allocation for a congested training camp schedule should be emphasized.

\section{Conclusions}

The present study shows that changes in the RPE, sRPE, HR zone, and running patterns were not asso- ciated with general wellness, recovery scoring guide, resting HR responses, or HRV in a short-term overseas training camp. The absence of fluctuations of recovery status and cardiac responses is not associated with changes in training or match loads. The players' recovery status and intensity of running patterns during an overseas training camp were not influenced by the accumulation of TL in a short-term period. It is practical to use a comprehensive assessment to monitor external and internal training/match loads during a short-term overseas training camp.

\section{Disclosure statement}

No author has any financial interest or received any financial benefit from this research.

\section{Conflict of interest}

The authors state no conflict of interest.

\section{References}

1. Baroni BM, Couto W, Leal Junior ECP. Descriptivecomparative study of aerobic performance parameters between soccer and futsal athletes [in Portuguese]. Rev Bras Cineantropom Desempenho Hum. 2011;13(3): 170-176; doi: 10.5007/1980-0037.2011v13n3p170.

2. Caetano RA, Voser RC, Moraes JC, Cardoso MS. Analysis of ball possession time and its influence in results of Futsal World Championship [in Portuguese]. Rev Bras Futsal Futebol. 2015;7(23):16-20.

3. Berdejo-del-Fresno D. A review about futsal. Am J Sports Sci Med. 2014;2(3):70-70; doi: 10.12691/ajssm-2-3-0.

4. Moore R, Bullough S, Goldsmith S, Edmondson L. A systematic review of futsal literature. Am J Sports Sci Med. 2014;2(3):108-116; doi: 10.12691/ajssm-2-3-8.

5. Dogramaci SN, Watsford ML, Murphy AJ. Time-motion analysis of international and national level futsal. J Strength Cond Res. 2011;25(3):646-651; doi: 10.1519/ JSC.0b013e3181c6a02e.

6. Barbero-Alvarez JC, Soto VM, Barbero-Alvarez V, Granda-Vera J. Match analysis and heart rate of futsal players during competition. J Sports Sci. 2008;26(1): 63-73; doi: 10.1080/02640410701287289.

7. Makaje N, Ruangthai R, Arkarapanthu A, Yoopat P. Physiological demands and activity profiles during futsal match play according to competitive level. J Sports Med Phys Fitness. 2012;52(4):366-374.

8. Jones CM, Griffiths PC, Mellalieu SD. Training load and fatigue marker associations with injury and illness: a systematic review of longitudinal studies. Sports Med. 2017;47(5):943-974; doi: 10.1007/s40279-016-0619-5.

9. Halson SL. Monitoring training load to understand fatigue in athletes. Sports Med. 2014;44(Suppl 2):139 147; doi: 10.1007/s40279-014-0253-z.

10. Thorpe RT, Atkinson G, Drust B, Gregson W. Monitoring fatigue status in elite team-sport athletes: implica- 
tions for practice. Int J Sports Physiol Perform. 2017; 12(Suppl 2):S227-S234; doi: 10.1123/ijspp.2016-0434.

11. Foster C, Florhaug JA, Franklin J, Gottschall L, Hrovatin LA, Parker S, et al. A new approach to monitoring exercise training. J Strength Cond Res. 2001;15(1):109115; doi: 10.1519/00124278-200102000-00019.

12. Miloski B, Moreira A, Andrade FC, Freitas VH, Peçanha T, Nogueira RA, et al. Do physical fitness measures influence internal training load responses in high-level futsal players? J Sports Med Phys Fitness. 2014;54(5): 588-594.

13. Bellenger CR, Fuller JT, Thomson RL, Davison K, Robertson EY, Buckley JD. Monitoring athletic training status through autonomic heart rate regulation: a systematic review and meta-analysis. Sports Med. 2016;46(10): 1461-1486; doi: 10.1007/s40279-016-0484-2.

14. Nakamura FY, Pereira LA, Rabelo FN, Flatt AA, Esco MR, Bertollo M, et al. Monitoring weekly heart rate variability in futsal players during the preseason: the importance of maintaining high vagal activity. J Sports Sci. 2016;43(24):2262-2268; doi: 10.1080/02640414.2016. 1186282 .

15. Dellal A, Lago-Peñas C, Rey E, Chamari K, Orhant E. The effects of a congested fixture period on physical performance, technical activity and injury rate during matches in a professional soccer team. Br J Sports Med. 2015;49(6):390-394; doi: 10.1136/bjsports-2012-091290.

16. Schneider C, Hanakam F, Wiewelhove T, Döweling A, Kellmann M, Meyer T, et al. Heart rate monitoring in team sports - a conceptual framework for contextualizing heart rate measures for training and recovery prescription. Front Physiol. 2018;9:639; doi: 10.3389/ fphys.2018.00639.

17. Fox JL, Stanton R, Sargent C, Wintour SA, Scanlan AT. The association between training load and performance in team sports: a systematic review. Sports Med. 2018; 48(12):2743-2774; doi: 10.1007/s40279-018-0982-5.

18. McLaren SJ, Macpherson TW, Coutts AJ, Hurst C, Spears IR, Weston M. The relationships between internal and external measures of training load and intensity in team sports: a meta-analysis. Sports Med. 2018; 48(3):641-658; doi: 10.1007/s40279-017-0830-z.

19. Rabbani A, Baseri MK, Reisi J, Clemente FM, Kargarfard M. Monitoring collegiate soccer players during a congested match schedule: heart rate variability versus subjective wellness measures. Physiol Behav. 2018;194: 527-531; doi: 10.1016/j.physbeh.2018.07.001.

20. Faulkner JA. Physiology of swimming and diving. In: Falls HB (ed.), Exercise physiology. New York: Academic Press; 1968 ; 415-446.

21. Matiegka J. The testing of physical efficiency. Am J Phys Anthropol. 1921;4(3):223-230; doi: 10.1002/ajpa.133 0040302.

22. Rocha MSL. Bone weight of the Brazilian of both sexes aged 17-25 years [in Portuguese]. Arq Anat Antropol. 1975;1:445-451.
23. Würch A. Women and sport [in French]. Med Sport Française. 1974;4(1):441-445.

24. Borg E, Borg G, Larsson K, Letzter M, Sundblad BM. An index for breathlessness and leg fatigue. Scand J Med SciSports.2010;20(4):644-650;doi:10.1111/j.1600-0838. 2009.00985.x.

25. Pianosi PT, Huebner M, Zhang Z, McGrath PJ. Dalhousie dyspnea and perceived exertion scales: psychophysical properties in children and adolescents. Respir Physiol Neurobiol. 2014;199:34-40; doi: 10.1016/j.resp.2014. 04.003.

26. Kenttä G, Hassmén P. Train smart: avoid overtraining syndrome [in Swedish]. Stockholm: SISU Idrottsböcker; 1999.

27. McLean B, Coutts AJ, Kelly V, McGuigan MR, Cormack SJ. Neuromuscular, endocrine, and perceptual fatigue responses during different length between-match microcycles in professional rugby league players. Int J Sports Physiol Perform. 2010;5(3):367-383; doi: 10.1123/ ijspp.5.3.367.

28. Cohen J. A power primer. Psychol Bull. 1992;112(1): 155-159; doi: 10.1037/0033-2909.112.1.155.

29. Rodrigues VM, Ramos GP, Mendes TT, Cabido CET, Melo ES, Condessa LA, et al. Intensity of official futsal matches. J Strength Cond Res. 2011;25(9):2482-2487; doi: 10.1519/JSC.0b013e3181fb4574.

30. Clemente FM, Nikolaidis PT. Profile of 1-month training load in male and female football and futsal players. Springerplus. 2016;5(1):694; doi: 10.1186/s40064016-2327-x.

31. Stanley J, Peake JM, Buchheit M. Cardiac parasympathetic reactivation following exercise: implications for training prescription. Sports Med. 2013;43(12):12591277; doi: 10.1007/s40279-013-0083-4.

32. Plews DJ, Laursen PB, Stanley J, Kilding AE, Buchheit M. Training adaptation and heart rate variability in elite endurance athletes: opening the door to effective monitoring. Sports Med. 2013;43(9):773-781; doi: 10.1007/s40279-013-0071-8.

33. Buchheit M. Monitoring training status with HR measures: do all roads lead to Rome? Front Physiol. 2014; 5:73; doi: 10.3389/fphys.2014.00073. 